\title{
Complutum
}

ISSN: 1131-6993

\section{Etnoarqueología en Tierra del Fuego (Argentina): una experimentación metodológica sobre las dinámicas sociales}

\author{
Albert García-Piquer ${ }^{1}$; Robert Carracedo-Recasens ${ }^{1}$; Assumpció Vila-Mitjà² Jordi Estévez ${ }^{1}$
}

Recibido: 7 de julio de 2016 / Aceptado: 1 de marzo de 2017

Resumen. Desde hace más de 25 años se han llevado a cabo en Tierra del Fuego (Argentina) una serie de proyectos etnoarqueológicos hispano-argentinos dirigidos a contrastar arqueológicamente el registro etnográfico de sociedades cazadoras-recolectoras. El principal objetivo ha sido el desarrollo metodológico para un adecuado reconocimiento de la organización social de estas sociedades que pudiera aplicarse a contextos arqueológicos. Para ello adoptamos una aproximación integral -arqueológica, etnográfica, tafonómica y experimental-a la que denominamos "Etnoarqueología experimental". En el marco de estos proyectos excavamos varios yacimientos arqueológicos del siglo XIX, es decir, correspondientes al período de contacto europeo con las sociedades indígenas y del cual se dispone amplia información etnográfica. En el trabajo aquí presentado expondremos los diferentes proyectos y sus conclusiones más importantes, concentrándonos en los resultados de la investigación en dos de los asentamientos Yámana excavados durante estos proyectos, Túnel VII y Lanashuaia, ubicados ambos en la costa norte del Canal Beagle.

Palabras clave: Tierra del Fuego; Etnoarqueología; sociedades cazadoras-recolectoras; análisis intra-site; organización social; metodología.

\section{[en] Ethnoarchaeology in Tierra del Fuego (Argentina): a Methodological Experiment on Social Dynamics}

\begin{abstract}
For over 25 years several Spanish-Argentine ethnoarchaeological projects have been conducted in Tierra del Fuego (Argentina) in order to contrast archaeologically the ethnographic record of Hunter-Gatherer societies. The main objective has been the development of a methodology capable to rebuild the social organization of these societies. A methodology that later could be applied to other archaeological contexts. We adopted a comprehensive-archaeological, ethnographic, taphonomic and experimental approach - and we call it "Experimental Ethnoarchaeology". In the frame of these projects several archaeological sites dated 19th century were excavated. Therefore, these sites belong to the period of European contact with native societies, from which broad ethnographic data is available. In this paper, we outline the various projects that have been carried out and point the most remarkable key findings. However, the discussion will focus on comparing the results of two Yamana settlements, Túnel VII and Lanashuaia, both located on the north coast of the Beagle Channel.
\end{abstract}

Keywords: Tierra del Fuego; Ethnoarchaeology; Hunter-Gatherer societies; Intra-site Analysis; Social Organizations; Methodology.

Sumario. 1. Introducción. 2. Perspectiva teórico-metodológica sobre la Etnoarqueología. 3. Resumen de los proyectos etnoarqueológicos en Tierra de Fuego. 4. El análisis de los concheros Túnel VII y Lanashuaia. 4.1. Presentación de los yacimientos. 4.2. Metodología. 4.3. Resultados. 5. Discusión. 5.1. Reflexiones específicas al caso de estudio. 5.2. Algunas reflexiones más generales. 6. Conclusiones y líneas de trabajo abiertas.

Cómo citar: García-Piquer, A. et al. (2017): Etnoarqueología en Tierra del Fuego (Argentina): una experimentación metodológica sobre las dinámicas sociales. Complutum, 28(2): 307-323. 


\section{Introducción}

En el presente artículo exponemos las motivaciones y algunas de las reflexiones y conclusiones substantivas fruto de las investigaciones llevadas a cabo desde 1986 por un numeroso grupo de trabajo formado principalmente por investigadores del Consejo Superior de Investigaciones Científicas (CSIC) en Barcelona, de la Universidad Autónoma de Barcelona (UAB) y del Centro Austral de Investigaciones Científicas (CADIC-CONICET) de Argentina. Durante más de 20 años se han encadenado con este grupo una serie de proyectos de investigación hispano-argentinos en la Isla Grande de Tierra del Fuego, en el extremo sur de Suramérica (Estévez y Vila-Mitjà 1996; Piana et al. 1992; Vila-Mitjà et al. 2007).

Con el objetivo primordial de resolver un problema histórico concreto, el proceso de cambio en las sociedades cazadoras-recolectoras (en adelante, SCR) del registro prehistórico europeo, se propuso el desarrollo y la verificación de metodologías de análisis e interpretación arqueológica (Estévez y VilaMitjà 1996). Se buscaba contrastar dinámicas y leyes generales para el modo de producción cazador-recolector; entre ellas, la tesis de la «Contradicción principal» $»^{3} \mathrm{y}$ de la división sexual del trabajo como mecanismo social en la gestión de esta contradicción (Argelés y VilaMitjà 1993; Estévez et al. 1998), así como investigar las estrategias de organización social y su arqueologización en el espacio de un yacimiento (Estévez 2000). Con estos objetivos en mente planteamos una experimentación etnoarqueológica en Tierra del Fuego, entendiendo la Etnoarqueología como una interfase para el desarrollo metodológico -tanto de la disciplina arqueológica como de la etnográfica- a través de un caso concreto de estudio. Para ello, se propuso abordar simultáneamente desde las fuentes etnográficas y con metodología arqueológica el análisis de una sociedad cazadora-pescadora-recolectora sub-actual, es decir, histórica pero ya desaparecida: la sociedad yámana.

La Isla Grande de Tierra del Fuego (Fig. 1) es un lugar privilegiado para este tipo de investigación. Por un lado, la costa del Canal Beagle tiene un ecosistema relativamente poco alterado, con una alta visibilidad y abundancia de yacimientos arqueológicos. Además, desde 1975 la zona es objeto de un extenso trabajo arqueológico que ha permitido recuperar una secuencia cronológica con hasta seis milenios de antigüedad (p.ej. yacimientos de Túnel I, $6680 \pm 210$ BP, o Lancha Packewaia, $4020 \pm$ 70 BP: Orquera y Piana 2009). Ello abría la puerta a realizar análisis en clave del proceso histórico que se había desarrollado en la zona.

Por otro lado, los grupos indígenas de Tierra del Fuego, considerados como un paradigma para las SCR prehistóricas, dieron lugar a una información etnográfica muy rica tanto en cantidad como en diversidad, destacando las minuciosas descripciones de Hyades y Deniker (1891) o la extensa etnografía de Gusinde (1937). Asimismo, se contaba con importantes colecciones de materiales etnográficos en museos americanos y europeos. Hace falta señalar que, aunque los primeros contactos esporádicos con navegantes y exploradores europeos se remontan a 1624, el impacto en el modo de vida cazador-pescador-recolector yámana fue limitado hasta mediados del siglo XIX, con la instalación de las misiones anglicanas y los primeros establecimientos rurales europeos. El relativo aislamiento, sumado a la rápida desintegración étnica y demográfica de estos grupos entre 1885 y 1900 (Piana y Orquera 1996) como consecuencia de este "contacto directo", sumado a todo lo anterior, ofrecía un entorno suficientemente controlado para la experimentación etnoarqueológica que se planteaba.

Así pues, se presenta en este trabajo un breve resumen de los objetivos y las motivaciones de los proyectos desarrollados, y de los yacimientos excavados. En segundo lugar, se presenta con más detalle la metodología empleada y los resultados obtenidos en la experimentación etnoarqueológica relativa a los concheros Túnel VII y Lanashuaia. Finalmente, las principales reflexiones fruto tanto de estas primeras experimentaciones como de proyectos posteriores serán presentadas en la discusión.

\section{Perspectiva teórico-metodológica sobre la Etnoarqueología}

La Arqueología es la única disciplina científica que puede afrontar el análisis de las sociedades llamadas prehistóricas, al ser el objeto de estudio de ésta los restos materiales producto de actividades sociales. Pese a ello, ya desde sus orígenes, la Arqueología se autoimpuso una presunta incapacidad para interpretar la organización social, asumiendo la invisibilidad o inmaterialidad de las relaciones sociales. 


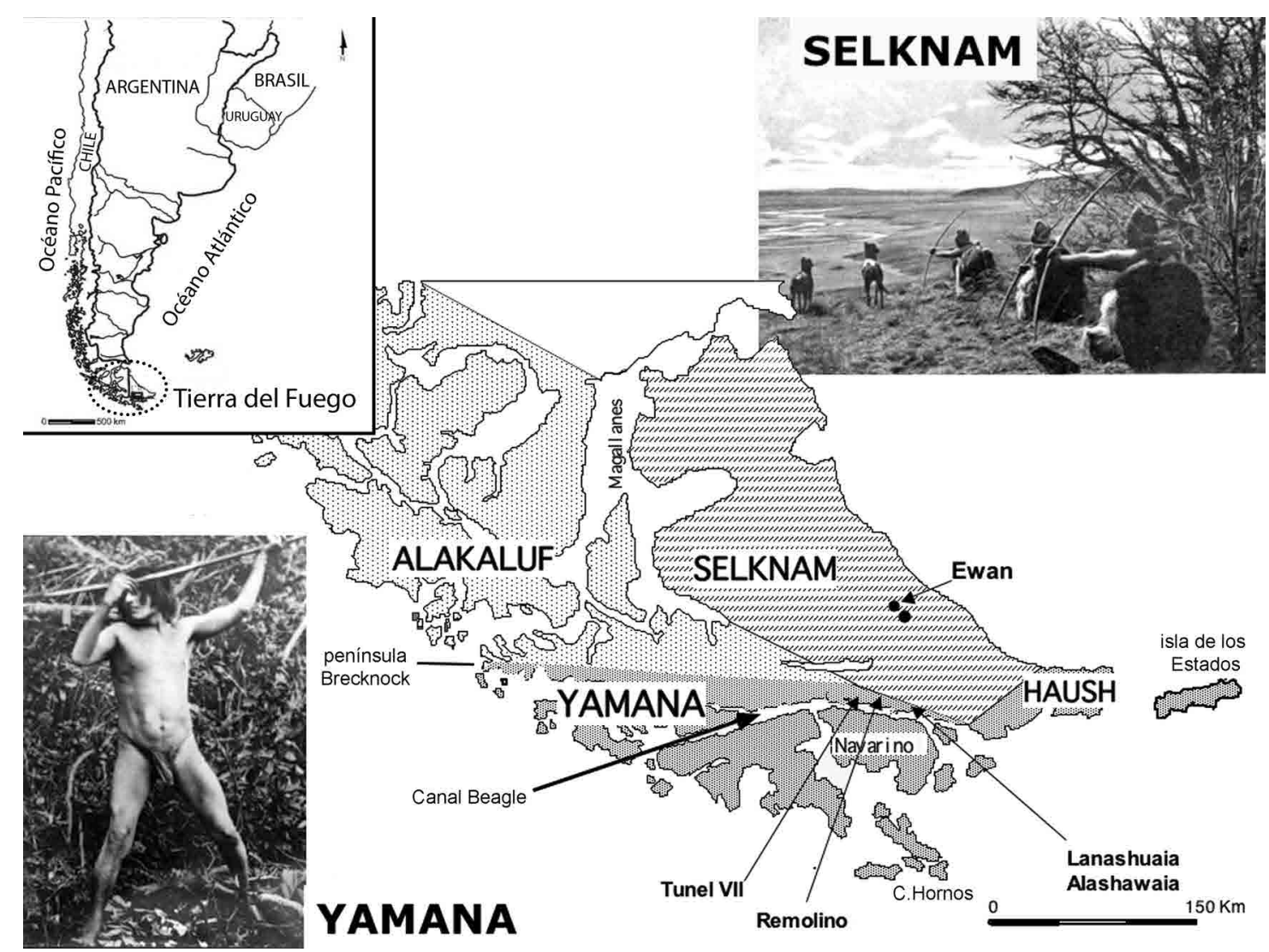

Figura 1. Mapa con el área de estudio y la localización de los yacimientos excavados durante los diversos proyectos.

Cuando se propuso esta experimentación etnoarqueológica, en los años 80 , la carencia de una metodología arqueológica para representar el conjunto de las estrategias de producción y reproducción en SCR prehistóricas había comportado que su estudio, especialmente en el caso de las sociedades paleo-mesolíticas, fuera campo de especulaciones y de inferencias sociales sin contrastación real. A pesar de la extendida crítica al uso o abuso de la analogía etnográfica a partir de la segunda mitad del siglo pasado, estas inferencias se habían apoyado consciente o inconscientemente en analogías, fundamentalmente etnográficas (ver crítica en Wobst 1978; Wylie 1985; Gándara 1990).

Más de tres décadas después del boom de la etnoarqueología en la investigación AngloAmericana, los avances metodológicos han permitido un notable desarrollo cualitativo y cuantitativo de los modos de subsistencia y el paleoambiente que tuvieron las SCR prehistóricas. Sin embargo, sigue existiendo una limitación de la disciplina arqueológica para ofre- cer explicaciones sobre la organización social de los grupos del pasado. En muchos casos, esta organización social se sigue extrapolando de una teoría general sobre las SCR, forzando y homogeneizando los datos etnográficos, y partiendo de una correspondencia perfecta $-\mathrm{O}$ adaptación- entre el sistema subsistencial y la organización de la sociedad (Vila-Mitjà et al. 2004). Por otro lado, y como reacción, otros posicionamientos han buscado respuestas sociales alternativas en el plano especulativo, renunciando, desde nuestra perspectiva teórica, a la exigencia de un recorrido metodológico riguroso.

No es nuestra intención en el presente artículo dedicar una discusión en profundidad a los problemas derivados del uso de la analogía etnográfica (véase para ello Vila-Mitjà 2006). Baste señalar que ésta ha tendido a derivar en una transferencia acrítica de observaciones sesgadas hacia el pasado. El resultado de todo ello, además de la aceptación de una "naturaleza humana" esencial y generalizable, ha sido un relativo consenso en torno el "igua- 
litarismo" de las SCR prehistóricas y modernas, aun a pesar de que "igualitario" suela ir acompañado de un "excepto en edad y sexo". En este sentido, cabe señalar un creciente debate sobre la "emergencia de la desigualdad" o la "aparición de la violencia" en las denominadas SCR "complejas" así como en SCR en transición (véase p. ej. una síntesis de las discusiones del último encuentro de la Conference on Hunting and Gathering Societies en Prentiss et al. 2016). No obstante, este debate sigue sosteniéndose sobre unas presuntas e indefinidas relaciones igualitarias asumidas $a$ priori en las SCR consideradas foraging. Por otro lado, trabajos recientes con grupos actuales de estas SCR se han centrado en analizar el grado de complementariedad sexual y el food sharing (Dyble et al. 2016), o la relación entre patrones de movilidad y co-residencia y la igualdad sexual en la capacidad de decidir (Hill et al. 2011; Dyble et al. 2015). De nuevo, las conclusiones de estos trabajos se siguen transfiriendo mediante analogía hacia el pasado, llegando a afirmar que «increased sex egalitarianism in human evolutionary history may have had a transformative effect on human social organization» (Dyble et al. 2015).Frente a ello consideramos que el problema no es el uso de analogías en general. Tal y como ha señalado Gándara, ésta es «constitutiva de la inferencia arqueológica» (2006: 13). El reto que tenemos en Arqueología es la redefinición de "lo material", es decir, de formular una metodología adecuada al estudio socio-económico de las SCR prehistóricas.

Es con este objetivo final que recurrimos a la Etnoarqueología entendida en un sentido amplio, como una herramienta para generar hipótesis, para evaluar y repensar la metodología arqueológica. Consideramos que la organización social no se puede extrapolar directamente de la economía sensu strictu, es decir, de los restos de la explotación de recursos, ni a través de analogía etnográfica directa, actualismos o simple determinismo ecológico. Por esta razón, no se recurrió a un trabajo arqueológico en sociedades modernas-actuales para verificar hipótesis de correlación entre conducta y restos materiales, ni tampoco a analogías formales derivadas de observaciones en el presente para ayudar a la interpretación del pasado. Se planteó una Etnoarqueología en cuanto que interfase experimental para el desarrollo metodológico en arqueología, donde las variables estuvieran controladas y fuera posible evaluar el ajuste de la metodología (ver discusión en Vila-Mitjà 2011). Así pues, al considerarla un experimento, propusimos "Etnoarqueología Experimental" como denominación genérica a este acercamiento etnoarqueológico (VilaMitjà y Piana 1993).

En definitiva, mediante la práctica etnoarqueológica queríamos aprehender los rasgos definitorios de unas sociedades etnográficamente documentadas y redescubrirlos a través de la arqueología. Mediante la contrastación, respectivamente, de las fuentes indirectas y directas de una misma sociedad, se pretendía ver cómo se materializan los rasgos esenciales del modo de producción-reproducción y de las relaciones sociales cazadoras-recolectoras en el registro arqueológico. Durante este proceso, buscando los indicadores arqueológicos de esos rasgos, y sus relaciones, construiríamos metodología (Estévez y Vila-Mitjà 1996).

\section{Resumen de los proyectos etnoarqueológicos en Tierra de Fuego}

Durante el primer proyecto, "Contrastación arqueológica de la imagen etnográfica de los canoeros magallánico-fueguinos de la costa norte del Canal Beagle" (1986-1994) el objetivo fue caracterizar en lo esencial la imagen etnográfica de la sociedad yámana (Estévez y Vila-Mitjà 1996) y averiguar si la propuesta de Contradicción Principal (Estévez et al. 1998) funcionaba, y en qué medida, para este tipo de sociedades que no controlan la reproducción de sus recursos. La realización del proyecto requirió primero el análisis crítico y la sistematización de las fuentes escritas e iconográficas, así como la revisión desde una óptica arqueológica de la casi absoluta totalidad de los materiales de los museos etnográficos (Estévez y Vila-Mitjà 2006a). El siguiente paso fue la evaluación arqueológica, mediante la primera excavación de un asentamiento, Túnel VII, un conchero de la época del contacto europeo localizado en la costa sur de la Isla Grande de Tierra del Fuego.

En el siguiente proyecto "Marine Resources at the Beagle Channel prior to the industrial Exploitation: An archaeological Evaluation" (1994-1997), el objetivo fue investigar la curva de temperatura paleoclimática a lo largo de los últimos 6.000 años y realizar una aproximación general al sistema de explotación de recursos a lo largo de la escala tempo- 
ral considerada (Albero et al. 1997). En este sentido, se compararon los recursos marinos representados en el registro arqueológico con los etnográficos y los actuales para evaluar las desviaciones y las modificaciones ocurridas. Se excavaron dos yacimientos arqueológicos, Lanashuaia (Piana et al. 2000) y Alashawaia, contemporáneos a Túnel VII pero situados a $60 \mathrm{~km}$ de distancia y enclavados en un biotopo bien distinto, para evaluar la variabilidad en los asentamientos y contrastar las hipótesis surgidas en las campañas anteriores.

A continuación, con el proyecto "Sociedad $y$ Ritual de los últimos cazadores-recolectores del Canal Beagle (Argentina)" (2000-2001) se cubrieron los aspectos relacionados con los procesos de reproducción social. Dada la importancia crítica de los procesos de mantenimiento del sistema a través de las actividades específicamente destinadas al refuerzo de los roles sexuales-sociales y, al mismo tiempo, de la criticalidad de la información que se puede obtener a partir de las actividades funerarias, necesitábamos excavar un contexto singular vinculado a actividades no cotidianas de reproducción social y un contexto funerario. Con tal objetivo se localizó y excavó la choza ritual construida en la Estancia Remolinos (Vila-Mitjà 2004; Vila-Mitjà et al. 2004), en la cual se había celebrado en 1920 una ceremonia Ciexaus. Esta ceremonia colectiva de iniciación fue registrada minuciosamente por el etnógrafo Martin Gusinde (1937). Asimismo, también se excavó el contexto funerario Mischiuen III, el enterramiento de una mujer joven en un abrigo rocoso (Vila-Mitjà et al. 2006).

Al año siguiente (2001-2002), el objetivo principal del proyecto "Desarrollo de nuevos sistemas de registro tridimensional" fue la incorporación de un sexto yacimiento -Mischiuen VIII- con el objetivo de experimentar sobre el uso de GIS y el registro digital de imágenes computarizadas para facilitar la recuperación de un registro tridimensional, su evaluación en tiempo real y la representación estratigráfica detallada de las subunidades aisladas con el método desarrollado para su excavación.

Los dos proyectos desarrollados entre 2002 y 2005: "Sociedad y ritual en grupos cazadores-recolectores: El uso del bosque como espacio ritual entre los Selk'nam de Tierra del Fuego" y "Ritual en grupos cazadores-recolectores: Espacios rituales y espacios domésticos entre los Selk'nam de Tierra del Fuego
(Argentina)" tuvieron como objetivo investigar sitios rituales y de habitación selk'nam junto a la costa oriental de Tierra del Fuego. En este marco, se analizó la variabilidad de dos yacimientos relacionados, Ewan I y Ewan II (Vila-Mitjà et al. 2004, Piqué y Mansur 2012), evaluando su posible caracterización mediante el registro arqueológico.

A modo de síntesis, en el desarrollo de los proyectos descritos se han llevado a cabo excavaciones arqueológicas en cinco asentamientos, en dos inhumaciones y en dos cabañas ceremoniales de dos de las agrupaciones indígenas fueguinas: yámana -la litoral meridional canoera- y selk'nam -la septentrional pedestre ${ }^{4}$.

\section{El análisis de los concheros Túnel VII y Lanashuaia}

Uno de los principales objetivos de esta experimentación etnoarqueológica era contrastar la relación entre organización espacial y relaciones sociales, así como las causas de la variabilidad evidente en el registro arqueológico. El planteamiento inicial que teníamos era que la organización interna de una unidad social se refleja en la gestión del espacio habitado (Estévez et al. 1984). Por tanto, del estudio de la localización de la producción, la distribución y el consumo, y de las estrategias organizativas resultantes, centradas en el acondicionamiento y la limpieza del espacio, debería ser factible extraer datos relativos a las relaciones sociales (Wünsch 1996).

Este enfoque requiere una metodología de excavación en extensión que permita un óptimo análisis del uso del espacio "micro", y que es diferente de la estrategia orientada a la verificación "macro" tal y como se ha planteado desde los paradigmas de la ecología cultural (Gassiot 2000). También requiere fijar las variables adecuadas en el estudio de los diferentes materiales en base al análisis de las estrategias de gestión (obtención, procesado, consumo, mantenimiento) de los elementos producidos y consumidos durante un determinado episodio de ocupación.

Así pues, con el objetivo elaborar una metodología instrumental adecuada para el análisis del registro arqueológico (la distribución, la disposición y la asociación espacial de los restos) propusimos excavar un asentamiento yámana de época etnográfica, Túnel VII. 
El registro etnográfico de los grupos yámana recoge una estricta división sexual del trabajo y una infravaloración de la mujer, enfatizada en las ceremonias de iniciación y en los mitos (Gusinde 1937; Hyades y Deniker 1891; ver Orquera y Piana 1999 para una completa recopilación de las fuentes etnográficas; ver Pedraza 2013 para una completa síntesis de las ceremonias y los mitos). Disponíamos, por tanto, de respuestas a nuestras preguntas sobre las estrategias concretas de organización social: qué tareas estaban normativamente reservadas a uno de los dos sexos; la localización de estas tareas en el asentamiento; el tiempo (trabajo) invertido en ellas y el valor social (sobrevaloración, invisibilización...) que dichas tareas tenían. Aunque parciales, someras o contradictorias a veces, estas descripciones permiten reconstruir críticamente una imagen etnográfica $\mathrm{y}$, en consecuencia, evaluar las posibilidades de la metodología arqueológica y su efectiva capacidad para la explicación de las dinámicas sociales. Para contrastar las hipótesis surgidas de su análisis, se excavó con la misma metodología otro yacimiento de la misma cronología, Lanashuaia. Presentamos a continuación ambos yacimientos, la metodología y los resultados arqueológicos.

\subsection{Presentación de los yacimientos}

Tanto Túnel VII como Lanashuaia (Fig. 1) son dos "concheros" situados en la parte meridional de la Isla Grande de Tierra de Fuego (Argentina). Ambos son plenamente representativos tanto de la morfología como de los procesos de formación de los yacimientos arqueológicos de asentamientos correspondientes a los momentos previos a la descomposición de la sociedad Yámana.

Túnel VII fue fechado por técnicas radiocarbónicas y dendrocronológicas. La datación AC 871, sobre una muestra de carbón correspondiente a un momento intermedio del conchero (sub-unidad B 135), indicó una antigüedad de $100 \pm 45$ antes de 1950 (Piana y Orquera 1996). Las determinaciones dendrocronológicas y la información relativa recuperada en el yacimiento (presencia, minoritaria, de cortes de filos metálicos en los restos óseos; un fragmento de húmero de oveja ${ }^{5}$ ) también apuntaban a su ocupación a lo largo del siglo XIX y, evidentemente, con anterioridad a la instalación en 1910-1915 de un aserradero sobre el yacimiento (ibid.). Por el contrario, las técnicas radiocarbónicas no permitieron datar con suficiente precisión la antigüedad del yacimiento de Lanashuaia (Piana et al. 2000: 456), aunque la ubicación sobre el nivel del mar y la presencia de restos de ovicáprido ha permitido proponer una probable cronología relativa del siglo XIX (ibid.).

Cabe señalar que el rápido proceso de formación, característico de los concheros, la neutralización de la acidez sedimentaria por efecto del carbonato cálcico, así como la ausencia de problemas tafonómicos destacados, producto de la cronología y la baja incidencia de posteriores actividades antrópicas, habían generado un excelente estado de conservación de estos yacimientos.

El yacimiento de Túnel VII se excavó a lo largo de cinco campañas (1988-1993). Está ubicado a orillas de la costa norte del Canal Beagle, en una pequeña caleta a unos diez ki-

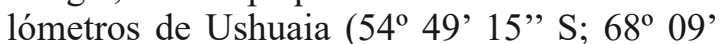
20 ” E). La excavación inicial afectó a $72 \mathrm{~m}^{2}$, reduciéndose posteriormente a un área determinada de $32 \mathrm{~m}^{2}$, en la cual se había identificado una topografía circular en cuyo centro se localizaban unas áreas afectadas por un foco de combustión. Su periferia se caracterizaba por la acumulación reiterada de desechos de procesos de trabajo y de residuos del consumo directo, con especial importancia de las valvas de los moluscos ingeridos (Estévez y Vila-Mitjà 1998).

Por su parte, el yacimiento de Lanashuaia se excavó durante tres campañas en 1995 , 1996 y 2005 (Piana et al. 2000; Verdún et al. 2015). Está situado en la costa norte del Canal Beagle, a unos $60 \mathrm{~km}$ al oeste de Túnel VII (54 52' 48.79" S; 67 $16^{\circ}$ '22.77” E). Forma parte de una gran concentración de concheros similares, distribuidos a lo largo de un lateral del istmo que separa dos bahías. El área excavada fue de $93 \mathrm{~m}^{2}$, comprendiendo la totalidad de una estructura anular (resultado del emplazamiento de una cabaña en ese lugar) y un amplio espacio externo a su alrededor.

\subsection{Metodología}

El proyecto comenzó con la recopilación y el análisis crítico y contextual de la información etnográfica y de los materiales depositados en los museos etnográficos. Al margen de las excavaciones de enterramientos y cabañas rituales, en el caso de los dos asentamientos que tratamos en este artículo el método de exca- 
vación tenía como objetivo desvelar el proceso de formación del sitio y su estructuración interna, tratando de armonizar la excavación de superficies extensas con una identificación estratigráfica muy minuciosa. Para ello se llevaron a cabo excavaciones en extensión, con sectores de $1 \mathrm{~m}^{2}$ divididos a su vez en subsectores de $0,50 \mathrm{~m}^{2}$. Todos los restos mayores de $1 \mathrm{~cm}^{2}$ fueron coordenados y registrados, usando ya en Lanashuaia una estación total, y todo el sedimento de los subsectores cribados con malla de $1 \mathrm{~mm}$.

Los yacimientos se excavaron mediante técnicas de extracción microestratigráfica, es decir, aislando y extrayendo cada una de las subunidades estratigráficas fruto de la rápida depositación de los restos de moluscos característica de los concheros de Tierra del Fuego. Para ello se desarrolló la metodología implementada por Orquera y Piana (1992). Posteriormente, esta microestratigrafía fue contrastada mediante el análisis de los remontajes, de los restos malacológicos (Verdún-Castelló 2014) y de la micromorfología de suelos (Villagran et al. 2011).

Con el objetivo de obtener una comprensión integral de las actividades humanas (Estévez 2000), se debía realizar una excavación en extensión pero al mismo tiempo tener en cuenta la antedicha micro-estratificación. Con este fin se realizó un programa de experimentación en cada yacimiento para elaborar el sistema de muestreo más apropiado. Además de columnas de muestreo clásicas -que se continuaron usando para verificar su validez como elemento referencial, se tomaron muestras homogeneizadas estadísticamente significativas para cada subunidad. Estas muestras fueron luego analizadas en laboratorio bajo lupa binocular por personas especialmente entrenadas (JuanMuns 1993).

Asimismo, y persiguiendo el mismo objetivo, se combinaron diversos métodos analíticos. Se llevó a cabo el análisis de la distribución espacial (Estévez y Clemente 2013) y las densidades de los residuos de bienes consumidos por categorías extraídas de la combinación del análisis arqueozoológico, tecnológico, de materias primas y de trazas de uso en materiales líticos y óseos; del remontaje de restos faunísticos y de talla; así como del análisis de fitolitos (Zurro 2010) y de ácidos grasos.

Por último, cabe mencionar que en paralelo se implementó un programa experimental con el objetivo de entender los procesos de forma- ción del yacimiento (p. ej. Mameli et al. 2002) y replicar los procesos de trabajo para verificar la traceología y al mismo tiempo aproximarnos a una escala de valor real (ver en Estévez y Vila-Mitjà 1996).

\subsection{Resultados}

En el caso de Túnel VII los resultados muestran una detallada secuencia de episodios discretos de ocupación determinados a partir de la superposición estratigráfica de diez fogones en el centro de una depresión circular, dominada por una sedimentación húmico-terrosa, generada por una corona de desechos acumulados, básicamente valvas de moluscos, en la periferia (Fig. 2). También se pudieron localizar pequeñas concavidades interpretadas como "agujeros de palos" que delimitan parcialmente esta área central más o menos circular de unos 3,5 $\mathrm{m}$ de diámetro (Estévez y Vila-Mitjà 2006b). A nivel global, esta serie de ocupaciones reiteradas a lo largo de un siglo representan la práctica totalidad de las estaciones del año, con una tendencia general hacia la explotación de recursos marinos (pesca, moluscos, pinnípedos). Sin embargo, ningún episodio tiene vinculada una pauta estacional específica ni en lo que respecta a la duración (algunos momentos de ocupación son breves, otros más largos) ni a las especies explotadas y sus frecuencias relativas, revelando una flexibilidad y una amplia variedad de estrategias (ibid.).

El yacimiento de Lanashuaia presenta tanto similitudes como diferencias con Túnel VII. Los agujeros de palos detectados permitieron delimitar también una estructura circular de 3-4 m de diámetro con un fuego principal en el centro (Fig. 3). No obstante, se ha documentado un único y largo episodio de ocupación, a lo mejor con un breve episodio de desocupación intermedio. Tampoco hay una orientación estacional clara (Piana et al. 2000: 459) aunque sí se detectaron cambios significativos en el número de restos de la fauna vertebrada: una concentración de huesos de cetáceo en la base de la ocupación es seguida por un predominio de restos de avifauna, de guanaco y pinnípedo; el final de la ocupación está dominado por ictiofauna (Verdún et al. 2015).

En ambos yacimientos están documentadas las actividades de talla y formatización de herramientas líticas, aprovechando preferentemente las materias primas más cercanas, tanto en el interior como en el exterior de la cabaña. 
El uso de las herramientas líticas es también bastante similar (con un predominio de trabajo sobre madera y tejidos animales blandos), aunque en Lanashuaia hay más herramientas para trabajar pieles y en Túnel VII más para la manufactura de objetos en hueso. Ello coincide con una elevada abundancia de restos de guanaco en el primero, y de objetos fabricados en tejidos animales duros en Túnel VII.

Algunos espacios de trabajo en el exterior se pueden vincular con actividades que generan gran cantidad de residuos (p. ej. descuartizamiento de piezas grandes, desbastado primario de talla lítica). Otros espacios interiores se vinculan con el procesado de piezas pequeñas o la elaboración de objetos de adorno y uso de instrumental fino (Estévez y Clemente 2013). El descuartizamiento de presas grandes se puede vincular en Túnel VII con el uso de instrumental elaborado con metal de origen europeo.

\section{Discusión}

\subsection{Reflexiones específicas al caso de estu- dio}

El método de excavación en Túnel VII y $L a-$ nashuaia permitió el establecimiento de fases microestratigráficas menores en lo que aparentemente podría considerarse un palimpsesto característico de los depósitos de concheros. El aislamiento y la extracción de subunidades estratigráficas muy detalladas permitió obtener una secuencia de imágenes temporales de grano fino, posibilitando identificar distintas ocupaciones del mismo lugar, reconocer patrones de organización espacial y establecer o descartar vínculos (véase Estévez y Clemente 2013; Vila-Mitjà et al. 2007).

El análisis del micro-espacio nos muestra una recurrencia en la configuración de un patrón básico más allá de las variaciones debidas a la explotación de recursos concretos o de la estacionalidad. Esto nos habla de la existencia de unas normas de gestión y distribución de las actividades productivas y de consumo, así como de la configuración de la unidad social básica (Fig. 4).

Los resultados muestran una correspondencia en general con las descripciones etnográficas de estos grupos altamente móviles y su patrón de asentamiento (Fig. 5), tanto en la conformación de las cabañas como en la práctica de su re-ocupación después de una somera re- construcción. Ello queda suficientemente bien reflejado en la recurrencia de la ocupación de Túnel VII, empleado intermitentemente hasta en diez ocasiones entre finales del siglo XVIII y finales del XIX. Por su parte, Lanashuaia también parece señalar hacia estrategias sociales y de subsistencia etnográficamente documentadas, como los episodios de agregación espacial debido al aprovechamiento de una ballena varada. Los resultados previamente presentados parecen apuntar a que el origen de la ocupación fue con gran probabilidad la explotación de una ballena minke (Balaenoptera acutorostrata). En este sentido, el estudio del conjunto de concheros del que forma parte $L a$ nashuaia, en concreto el alineamiento y la distancia entre los diferentes concheros, así como su localización en una misma cota sobre el nivel del mar, parecen apuntar hacia esa pauta en la gestión del espacio social (Fig. 6; Piana et al. 2000). Cabe señalar que la etnografía ha referido que estos episodios de agregación propiciados por una abundante y puntual disponibilidad de alimento podían incitar a la celebración de las largas ceremonias de iniciación yámana como el ciexaus (Gusinde 1937: 789-790) o el kina (ibid.: 898).Al margen de las recurrencias significativas que hemos señalado (Estévez y Clemente 2013) y de tendencias generales en la explotación de recursos, los sitios muestran una variabilidad no condicionada por el ritmo estacional de los recursos sino más bien por las ligeras variaciones temporales y espaciales del biotopo concreto. En Lanashuaia, a pesar del aprovechamiento inicial de la ballena, se documenta la explotación oportunista de otros recursos, así como un predominio final de la pesca una vez consumida aquélla y agotados los recursos alternativos más rentables. Ello se corresponde, de nuevo, con los datos etnográficos. En este sentido, Gusinde (1937: 541) señaló que era poca la variación de importancia de los recursos a lo largo del año.

Sin embargo, en ambos yacimientos, observamos una flexibilidad y una variabilidad mayor en el registro arqueológico que la recogida en el etnográfico. Por ejemplo, en Túnel VII y Lanashuaia se consumió una variedad de aves marinas y terrestres (Mameli y Estévez 2004) mucho mayor que la señalada por parte de los etnógrafos, incluyendo especies cuyo consumo se había negado categóricamente (es el caso de gaviotas, garzas o aves de rapiña: $\mathrm{Gu}-$ sinde 1937: 504) o con muy bajo rendimiento cárnico (cotorras, paseriformes u otras aves te- 
a

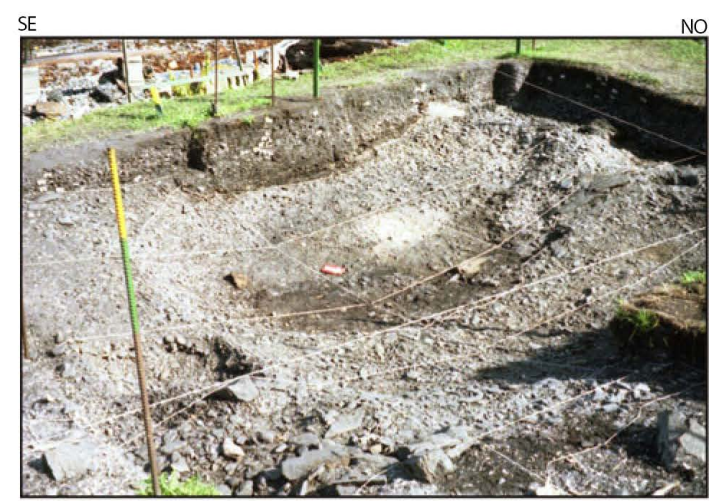

b

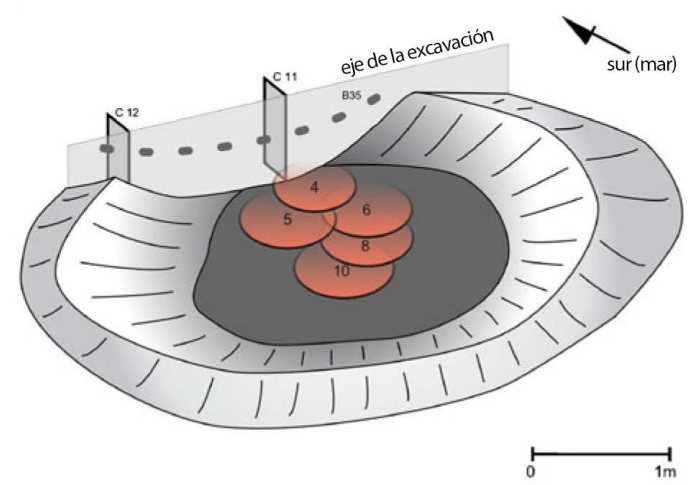

\section{C}
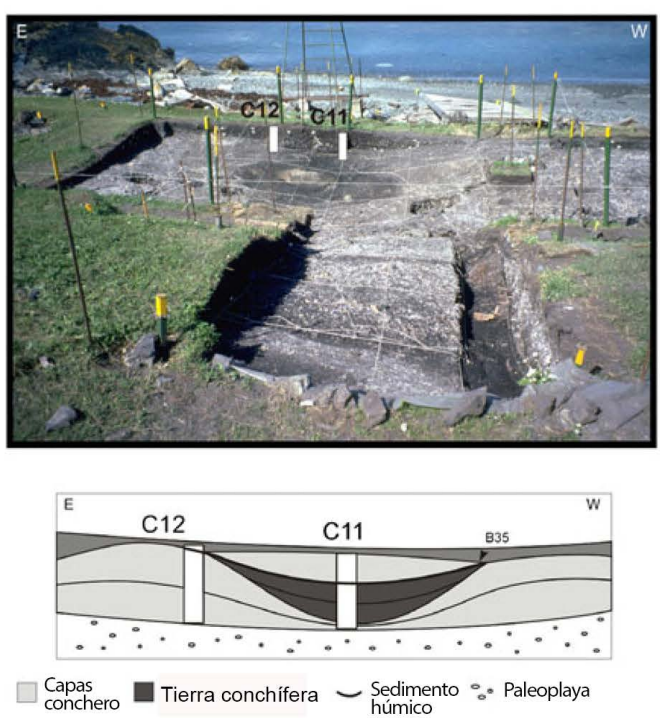

d
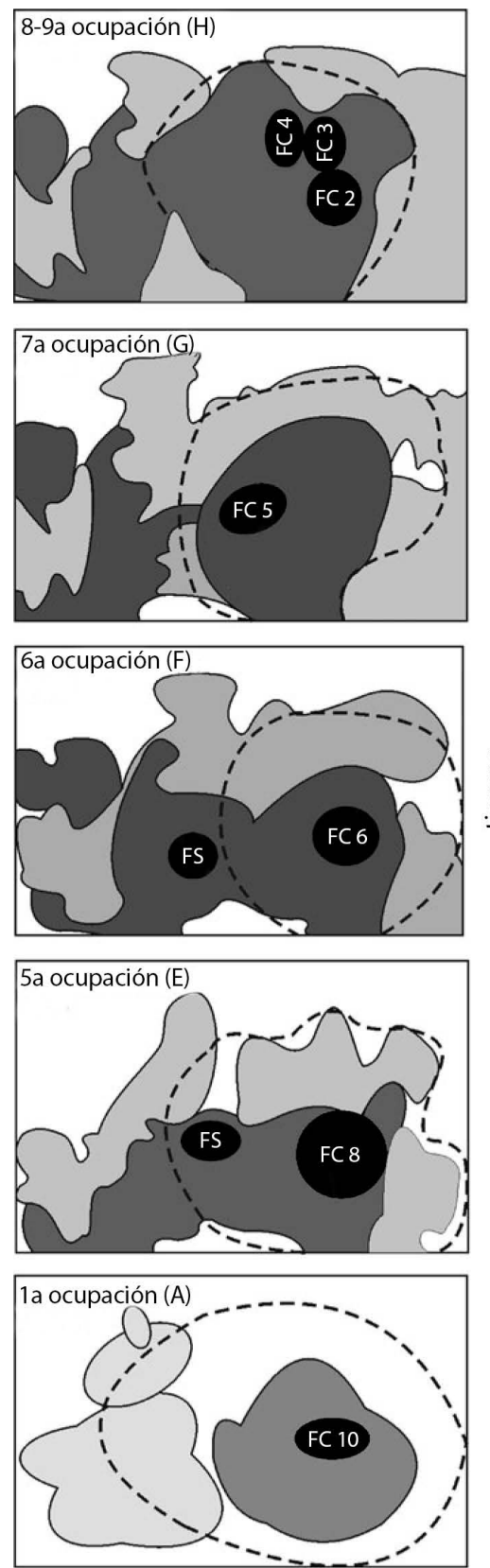

Conchero

Area central

FCFuego central FS Fuego secundario

Figura 2. a) Fotografía de Túnel VII con la primera ocupación (FC10) al descubierto. b) Localización de los fuegos 10, 8, 6, 5 y 4. c) Fotografía del yacimiento (arriba) y perfil esquemático de Túnel VII con las principales unidades macroestratigráficas (abajo). d) 5 de las 10 ocupaciones identificadas en Túnel VII.

rrestres pequeñas).

También se evidencia arqueológicamente el empleo de determinadas técnicas de caza no optimizadas, como la caza de pinnípedos con arco y flecha, que sin embargo etnográ- ficamente sólo está documentada con arpón (véase Hyades y Deniker 1891: 353; Gusinde 1937: 497-500). Así, aunque las puntas de arpón están bien representadas, también hemos documentado impactos de puntas de flecha en 


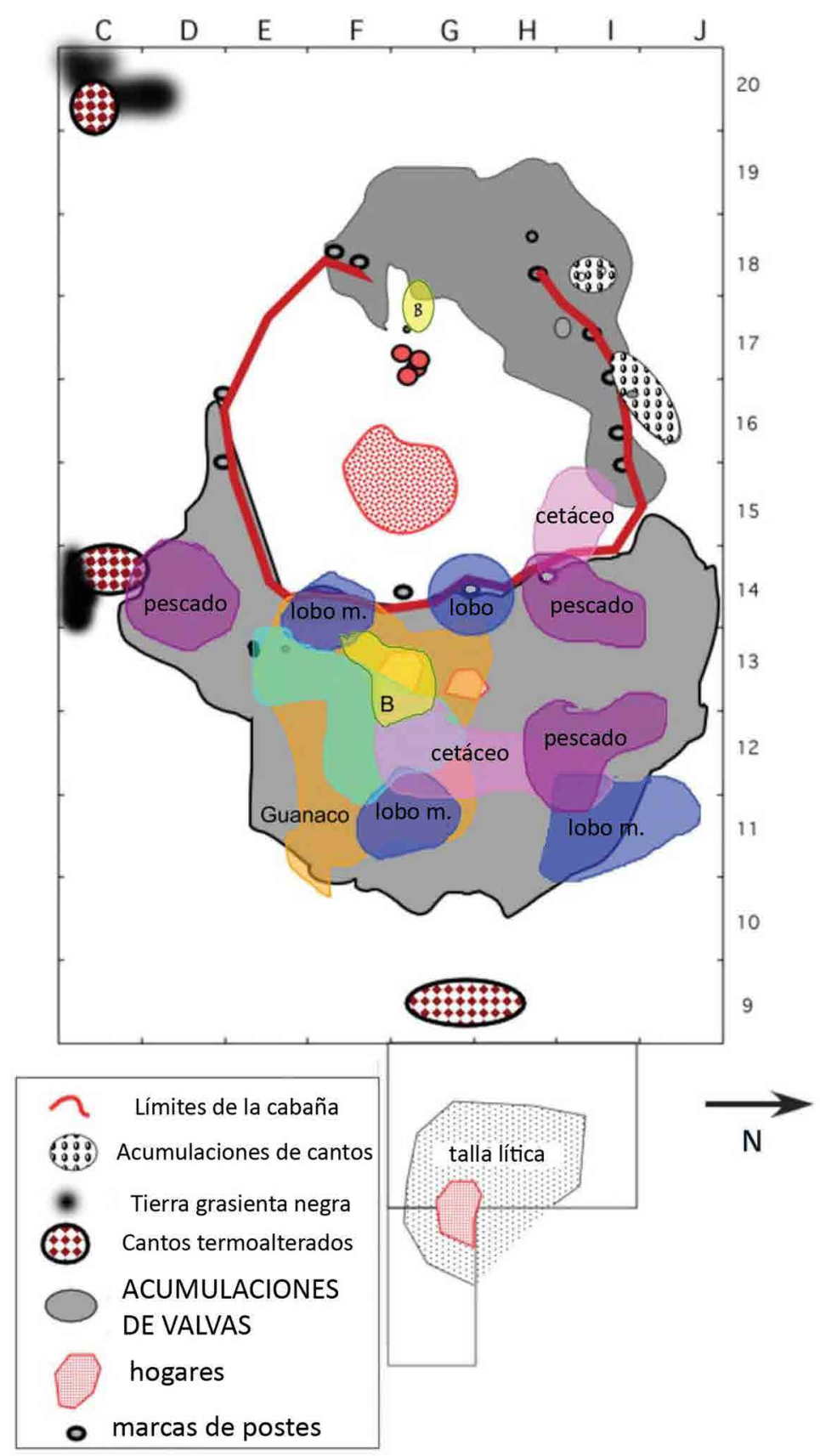

Figura 3. Distribución de las principales estructuras de la unidad de ocupación de Lanashuaia. Se muestran las concentraciones significativas de instrumentos en hueso (B) y restos de pescado, avifauna, pinnípedo, ballena y guanaco.

restos de pinnípedo (Fig. 7). De hecho, a pesar de que la etnografía minimice el uso del arco y flecha en estos grupos (Hyades y Deniker 1891: 360; Gusinde 1937: 450), la producción de puntas pedunculadas es especialmente relevante en todos los yacimientos yámana (Mameli et al. 2005). Más aún, se observa un considerable contraste entre el volumen de restos líticos recuperados en Túnel VII y Lanashuaia y la escasa atención que recibe la manufactura o uso de instrumentos líticos en la documentación etnográfica, así como su infrarrepresentación en las colecciones de objetos etnográficos (Estévez y Vila-Mitjà 2006a).

En definitiva, es lo que hemos definido como una estrategia de "especialización en 


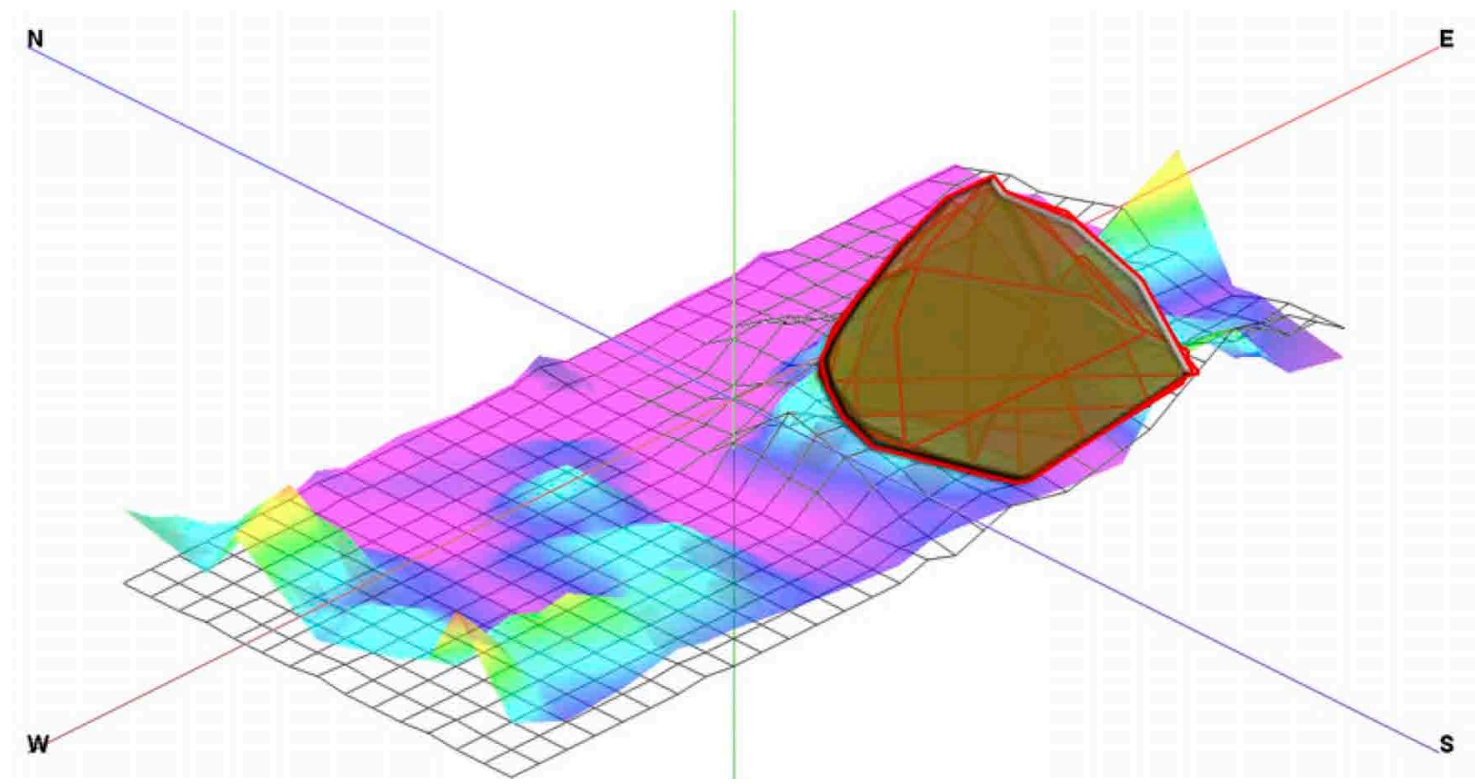

Figura 4. Gradiente en 3D de la distribución del valor acumulado a partir de las frecuencias de los residuos de fauna consumida. Altura y gradación de color señalan dos zonas de acumulación de restos en el yacimiento (zona oeste y periferia de la estructura de ocupación).

la no especialización" (Estévez y Vila-Mitjà 2006b), superando los modelos duales de forager/collector o especializado/oportunista. En otras palabras, documentamos una coexistencia de estrategias de subsistencia muy especializadas y comportamientos oportunistas.

\subsection{Algunas reflexiones más generales}

Aunque muy someramente, no podemos dejar de señalar algunas de las conclusiones significativas que nos han dejado el resto de proyectos realizados a lo largo de estos más de 25 años de Etnoarqueología experimental en Tierra del Fuego.

En primer lugar, las investigaciones permitieron demostrar la existencia de una continuidad tanto en los ecosistemas litoral e insular (Albero et al. 1997) como en los recursos explotados durante los últimos 6.000 años. El conjunto de instrumentos básicos se mantuvo estable pese algunas variaciones menores en la forma y decoración, aunque hay evidencias de momentos de crisis, experimentación e invención de nuevos útiles. Al final de la secuencia se observa, primero, una rápida incorporación de las nuevas materias primas europeas (vidrio y metal); seguidamente, de las mismas formas e instrumentos europeos. Con ello se demues- tra que supieron adaptar muy rápidamente la tecnología para sacar la máxima rentabilidad de las nuevas posibilidades que les ofrecía la llegada de nuevos materiales.

Sin embargo, no podemos hablar de una adaptación simple, estable ni exitosa sino de un esfuerzo dinámico por mantener el sistema social. Efectivamente, hay indicadores de reajustes tecnológicos y hiatos que pueden corresponder a crisis sociales. Pero hemos de admitir que las estrategias de reproducción desarrolladas permitieron finalmente una sostenibilidad después de 6000 años de existencia. Así podemos afirmar que las relaciones sociales dominaban las relaciones de subsistencia determinantes; el sistema social era menos flexible que las estrategias de subsistencia. Al final, la organización social no reaccionó lo suficientemente rápido como para compensar la caída demográfica causada por la violencia europea, las enfermedades y la explotación industrial de los recursos. La consecuencia visible de esto fue que las enfermedades así como la concentración y dispersión de la población causaron unas pérdidas demográficas importantes y la disolución de la sociedad yámana.

En segundo lugar, la excavación de yacimientos de las denominadas adaptaciones terrestres (Selk'nam) y marítimas (Yámana) 

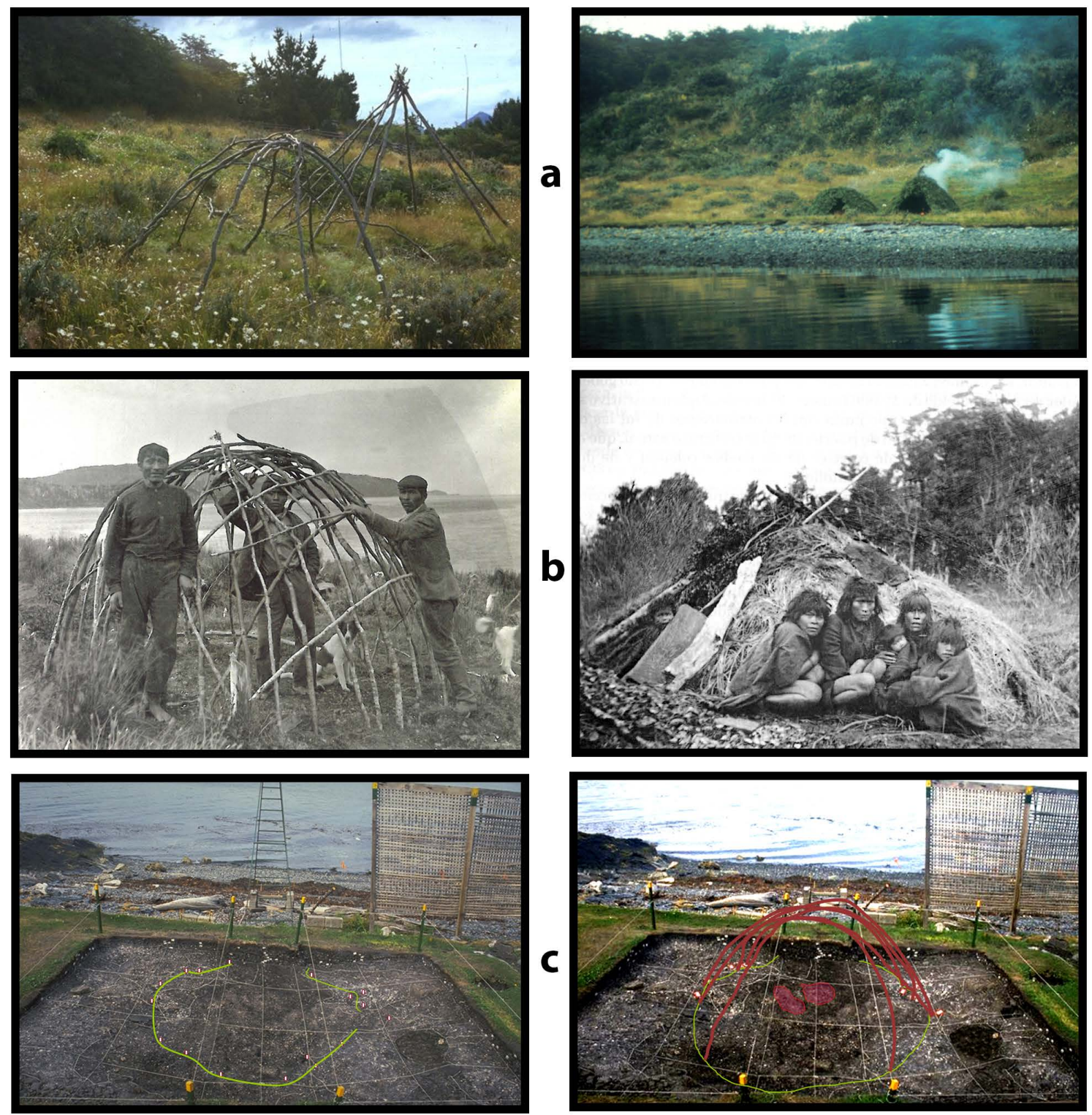

Figura 5. a) Réplicas experimentales de cabañas yámanas. b) Der:: Grupo de mujeres yámana delante de una choza (Fuente: Colección Mission Scientifique du cap Horn, 1882, Musée de l'Homme, Paris); Izq.: Armazón de una choza yámana (Fuente: South American Mission Society, 1892-1907). c) Reconstrucción de la cabaña de Túnel VII en base a los agujeros de palo identificados.

muestra que las "fronteras" descritas por la etnografía son muchas veces una proyección de prejuicios políticos. En Tierra del Fuego estas divisiones no son visibles en los restos arqueológicos. No podemos, pues, asumir las divisiones étnicas de la etnografía como un hecho, sino como consecuencias cambiantes de los diferentes grados de intensidad en el intercambio social y las necesidades reproductivas. En definitiva, debemos ir con cuidado a la hora de correlacionar conjunto arqueológico y cultura, ya sea ésta entendida en clave de adaptación o de categoría étnica.

\section{Conclusiones y líneas de trabajo abiertas}

Las contradicciones entre la evidencia arqueológica de Túnel VII y Lanashuaia y la información etnográfica sobre los grupos yámana permiten concluir que el registro etnográfico es subjetivo, está sesgado social e históricamente, 


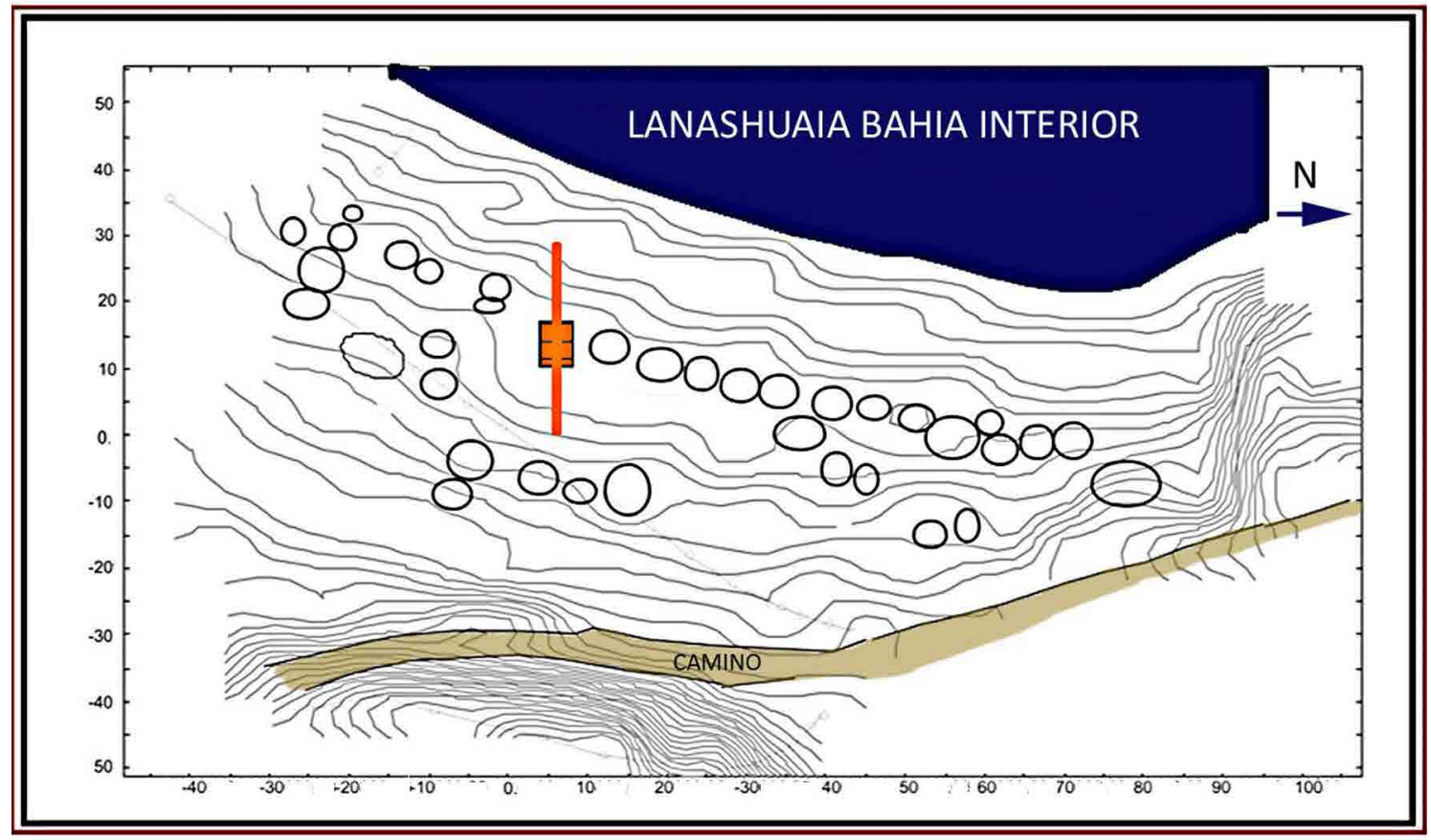

Figura 6. Relevamiento topográfico de la playa de Lanashuaia donde se puede apreciar la concentración de concheros. En el centro, la cuadrícula correspondiente a las dos primeras campañas.

y cambia a lo largo del tiempo. Como se ha visto en el caso yámana, las SCR eran y son dinámicas, flexibles y cambiaban muy rápido, incluso antes de este registro etnográfico. Así pues, la analogía formal, acrítica, puede ser válida en la etapa de sugerir hipótesis, pero no a la hora de interpretar la evidencia arqueológica. Sin embargo, los resultados expuestos en el presente y en otros trabajos (véase Piqué y Mansur 2011; Vila-Mitjà et al. 2004) también permiten concluir que una lectura crítica, contextualizada y contrastada de la amplia información etnográfica disponible sobre SCR ofrece oportunidades de investigar las dinámicas, las leyes generales del modo de producción cazador-recolector y sus correlatos materiales.

La excavación y análisis de estos dos yacimientos fueguinos ha funcionado como un experimento de control metodológico, permitiendo obtener una descripción de las actividades socio-económicas de los grupos cazadores-pescadores-recolectores que ocuparon Túnel VII y Lanashuaia. En ambos casos, los resultados indican que la distribución espacial de los residuos de producción y consumo no responde, ni en el interior ni en el exterior de la estructura de ocupación, a una depositación de carácter aleatorio. Sin embargo, desconocemos si esta organización espacial de las activi- dades antrópicas corresponde a una diferencia en el consumo, en la producción, o en ambos procesos, dentro de la unidad social. En otras palabras, a unas relaciones sociales no igualitarias entre sexos. Al inicio de este trabajo, se ha planteado que la organización social no se puede extrapolar directamente de las estrategias de subsistencia reconstruidas a partir de la evidencia arqueológica. Muchas de las actividades de trabajo que, según la etnografía $(\mathrm{Gu}-$ sinde 1937; Orquera y Piana 1999: 475-477), llevaban a cabo las mujeres yámana son más difíciles de reconocer en lo que se ha venido entendiendo por registro arqueológico, aun a pesar de requerir mayor esfuerzo y tiempo que otras más valoradas socialmente. Esta relación inversa entre valor real/objetivo (tiempo) y valor subjetivo (social) se ha podido reconocer en la mayoría de SCR (Waguespack 2005).

Dentro del marco de esta experimentación etnoarqueológica se propuso una teoría del valor en SCR (Barceló et al. 2006), con el objetivo de plantear una aproximación cuantitativa y objetiva a la desigualdad entre la producción/ consumo de los diferentes agentes sociales. La información arqueológica, etnográfica y experimental acumulada durante los diversos proyectos etnoarqueológicos hacía posible su aplicación experimental en el caso yáma- 


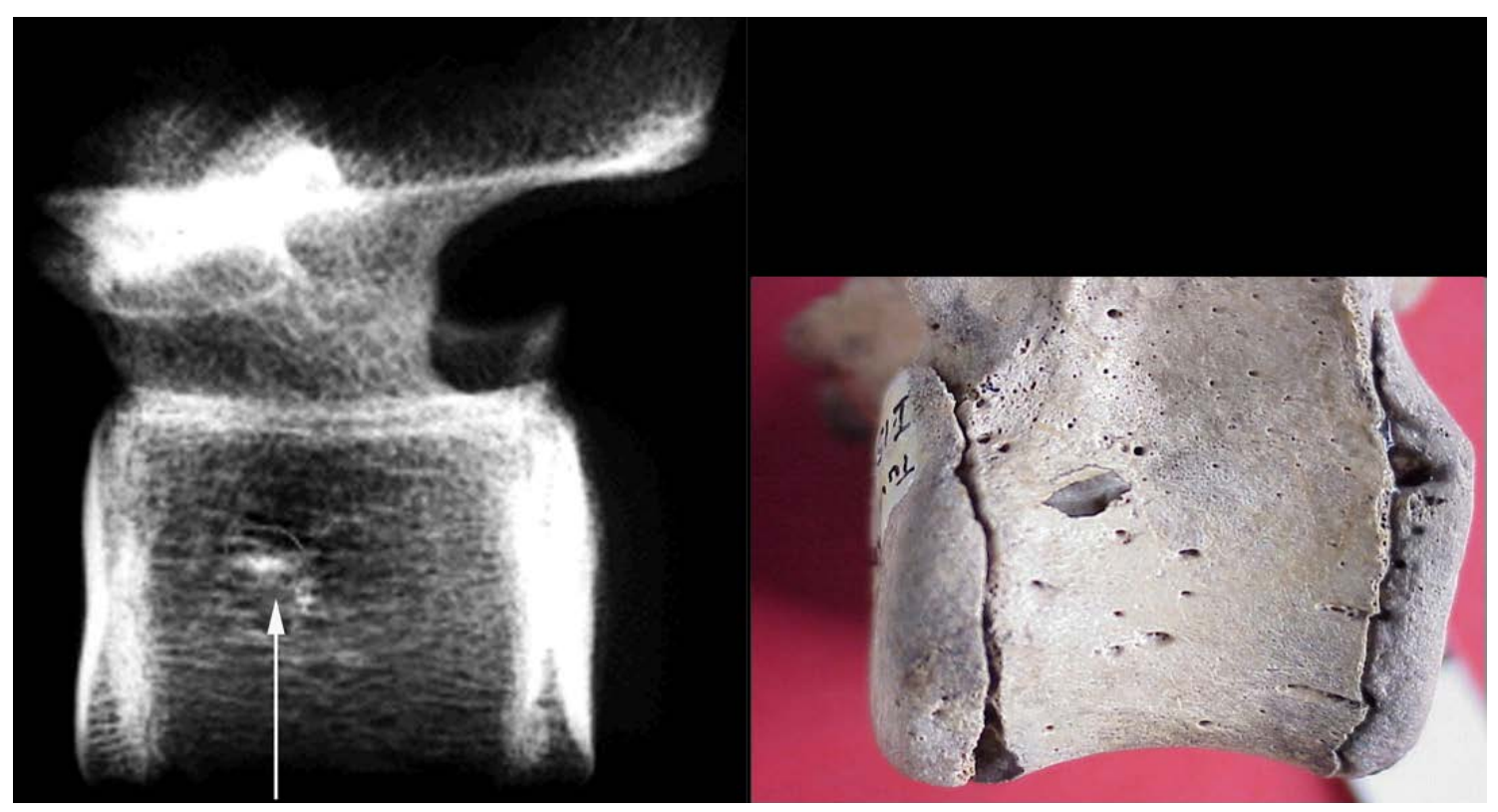

Figura 7. Vertebra de pinnípedo con una punta de flecha clavada.

na. Algunos resultados preliminares han sido presentados (Vila-Mitjà et al. 2010; Pérez-Rodríguez et al. 2016). Actualmente se está desarrollando una aproximación arqueológica a las normas sociales que regulan el consumo y la producción (la división sexual del trabajo) mediante un análisis de la organización espacial de Túnel VII y Lanashuaia en base a categorías analíticas resultado de esta propuesta cuantitativa. El objetivo es poder extraer indicadores arqueológicos para identificar la organización social de las SCR prehistóricas.

En este sentido, y para acabar, los resultados de estos proyectos etnoarqueológicos iniciados hace más de dos décadas muestran que, para acceder a la organización social de las SCR prehistóricas, es necesaria una reflexión teórica y metodológica que permita afinar y redefinir los límites de lo que se puede considerar "registro arqueológico" (concebido como la información que se consigue con el trabajo arqueológico: Vila-Mitjà 2011). Existe, de hecho, un interés renovado por desvelar la "invisibilidad" de los elementos ideológicos, simbólicos y sociales (p. ej. Hardy 2010). En este sentido, la Etnoarqueología experimental tal y como la hemos presentado puede ayudar a desarrollar propuestas metodológicas y contrastar modelos teóricos partiendo de una realidad conocida.

\section{Agradecimientos}

Trabajo realizado en el marco del proyecto de investigación predoctoral "Aproximación arqueológica al mantenimiento y la transmisión de las normas sociales en sociedades cazadoras-pescadoras-recolectoras" (2014FI_B916), financiado por la Generalitat de Catalunya-AGAUR. Los autores son miembros del grupo de investigación consolidado AGREST (2014SGR1169). Los diferentes proyectos etnoarqueológicos hispano-argentinos han sido posibles gracias a la financiación de las respectivas instituciones estatales de investigación (CSIC y CONICET, 2005AR0099 y el PIFCOO_08_00017), del Ministerio Español de Cultura y de Educación (DGICYT y MEC-EXCAV. EXT2003), el de Ciencia y Tecnología (HUM200601129, BHA2002-04109-C02, PGC2000-2434-E, UE95-0014 y PB98-0888) y el de Ciencia e Innovación (HAR2011-24356 de la D.G.E.S.I.C.), de la Generalitat de Catalunya (EXCAVA 2006-excav 0021) y de la Unión Europea (ALAMED CI1*CT93-0015). Agradecemos a todas las personas que han participado en estos proyectos de investigación. 


\section{Notas}

3. Con esta hipótesis a modo de ley explicativa se ha planteado que el modo de producción que define las SCR viene dado por un factor dinamizador interno, definido como Contradicción Principal entre «las condiciones sociales de los procesos de producción de bienes materiales y las de los procesos de reproducción biológica y social» (Estévez et al. 1998: 11). La especial articulación de estas relaciones es lo que permitiría entender la estabilidad o el cambio en este tipo de sociedades.

4. El resultado de dichos proyectos se puede encontrar en una serie de monografías (Treballs d'etnoarqueologia) editados por el CSIC.

5. La fecha más antigua conocida de introducción de los ovinos en la zona es 1867. Aunque con anterioridad los grupos yámana habrían podido recibir esporádicamente un ejemplar o piezas anatómicas de este animal desde algún barco, ello parece poco probable con anterioridad a 1830 (Piana et al. 2000).

\section{Bibliografía}

Albero, M.C.; Angiolini, F.E.; Piana, E. (1997): Holocene 14C Reservoir Effect at Beagle Channel (Tierra del Fuego, Argentina). Quaternary of South America and Antartic Peninsula, 4: 59-72.

Argelés, T.; Vila-Mitjà, A. (1993): De la contradicció, o de la diferència a l'explotació. L'Avenç: 1-3.

Barceló, J.A.; Iván, B.G.; Ignacio, C.; Estévez, J.; Mameli, L.; Pijoan-López, J.; Piqué, R.; Terradas, X.; Toselli, A. J.; Verdún, E.; Vila-Mitjà, A.; Zurro, D. (2006): Análisis etnoarqueológico del valor social del producto. Etnoarqueología de la Prehistoria: más allá de la analogía, Treballs d'etnoarqueologia 6 (Departament d'Arqueologia i Antropologia IMF-CSIC, eds.), CSIC, Madrid: 189-207.

Dyble, M.; Salali, G.D.; Chaudhary, N.; Page, A.; Smith, D.; Thompson, J.; Vinicius, L.; Mace, R.; Migliano, A.B. (2015): Sex equality can explain the unique social structure of hunter-gatherer bands. Science 348(6236): 796-798.

Dyble, M.; Thompson, J.; Smith, D.; Salali, G.D.; Chaudhary, N.; Page, A.E.; Vinicuis, L.; Mace, R.; Migliano, A.B. (2016): Networks of Food Sharing Reveal the Functional Significance of Multilevel Sociality in Two Hunter-Gatherer Groups, Current Biology, 26(15):2017-2021. doi:10.1016/j. cub.2016.05.064

Estévez, J.; Gasull, P.; Lull, V.; Sanhuja, M.E.; Vila-Mitjà, A. (1984): Arqueología como Arqueología. Propuesta para una terminología operativa. Primeras Jornadas de Metodología de Investigación Prehistórica, Soria 1981 (Subdirección General de Arqueología y Etnología, ed.), Ministerio de Cultura, Madrid: 293-298.

Estévez, J.; Vila-Mitjà, A. (coords.) (1996): Encuentros en los conchales fueguinos. Treballs d'Etnoarqueologia 1. CSIC i UAB, Bellaterra.

Estévez, J.; Vila-Mitjà, A. (1998): Tierra del Fuego, lugar de encuentros. Revista de Arqueologia Americana, 15: $187-219$.

Estévez, J.; Vila-Mitjà, A; Terradas, X.; Piqué, R; Taulé, M.; Gibaja, J.; Ruiz, G. (1998): Cazar o no cazar: ¿es ésta la cuestión? Boletín de Antropología Americana, 33: 5-24.

Estévez, J.; Vila-Mitjà, A. (2000): Estratigrafías en contexto. Krei, 5: 29-61.

Estévez, J.; Vila-Mitjà, A. (2006a): Colecciones de museos etnográficos en arqueología. Etnoarqueología de la Prehistoria: más allá de la analogía, Treballs d'etnoarqueologia 6 (Departament d'Arqueologia $\mathrm{i}$ Antropologia IMF-CSIC, eds.), CSIC, Madrid: 241-253.

Estévez, J.; Vila-Mitjà, A. (2006b): Variability in the lithic and faunal record through 10 reoccupations of a XIX century Yamana Hut. Journal of Anthropological Archaeology, 25(4): 408-423.

Estévez, J.; Clemente, I. (2013): Domestic Space: Analysis of the Activities of a Hunter-Gatherer Social Unit at the Southern End of the American Continent. The Archaeology of Household (M. Madella, G. Kovacs, B.K. Berzsenyi, I.B. Godino, eds.), Oxbow Books, Oxford: 67-85.

Gándara, M. (1990): La analogía etnográfica como heurística: lógica muestral, dominios ontológicos e historicidad. Etnoarqueología. Coloquio Bosch-Gimpera (Y. Suguiura, M.C. Serra, eds.), Instituto de Investigaciones Antropológicas, México: 43-82.

Gándara, M. (2006): La inferencia por analogía: más allá de la analogía etnográfica. Etnoarqueología de la Prehistoria: más allá de la analogía, Treballs d'etnoarqueologia 6 (Departament d'Arqueologia i Antropologia IMF-CSIC, eds.), CSIC, Madrid: 13-23.

Gassiot, E. (2000): Anàlisi arqueològica del canvi cap a l'explotació del litoral. Tesis doctoral. Universitat Autonòma de Barcelona.

Gusinde, M. (1937 [1986]): Los Indios de Tierra del Fuego. Tomo 2, Los Yámana. Centro Argentino de Etnología Americana, Buenos Aires. 
Hardy, K. (ed.) (2010): Archaeological Invisibility and Forgotten Knowledge: Conference Proceedings, Eódź, Poland, 5th-7th September 2007. Archaeopress, Oxford.

Hill, K.R.; Walker, R.S.; Božičević, M.; Eder, J.; Headland, T.; Hewlett, B.; Hurtado, A.M.; Marlowe, F.; Wiessner, P.; Wood, B.; 2011. Co-Residence Patterns in Hunter-Gatherer Societies Show Unique Human Social Structure. Science 331(6022): 1286-1289.

Hyades, P.; Deniker, J. (1891): Mission scientifique du cap Horn 1882-1883, Tome VII, Anthropologie, Ethnographie. Gauthier-Villard, Paris.

Juan-Muns, N. (1993): La pesca: alternativa econòmica pels yàmana de la costa del canal Beagle. Tesis doctoral. Universitat Autònoma de Barcelona.

Mameli, L.; Barceló, J.A.; Estévez, J. (2002): The Statistics of Archaeological Deformation Processes. Archaeological informatics: Pushing the envelope (G. Burenhult, G., J. Arvidssen, eds.), Archaeopress, Oxford: 221-232.

Mameli, L.; Estévez, J. (2004): Etnoarqueozoología de aves: el ejemplo del extremo sur americano. Treballs d'Etnoarqueologia, 5. CSIC, Madrid. 2004.

Mameli, L.; Estévez, J.; Piana, E.L. (2005): "Deep impact: stones in bones". Some though about the EthnoArchaeology contrast. A view from Tierra del Fuego (extreme south of America). Stone tools in ethnoarchaeological contexts (X. Terradas, ed.), Archaeopress, Oxford: 9-19.

Orquera, L.A.; Piana, E.L. (1992): Un paso hacia la resolución del palimpsesto. Análisis espacial en la arqueología patagónica (L.A. Borrero, J. L. Lanata, eds.), Ayllu SRL., Buenos Aires: 21-52.

Orquera, L. A.; Piana, E. L. (1999) La vida material y social de los Yámana. Instituto Fueguino de Investigaciones Científicas, Buenos Aires.

Orquera, L.A.; Piana, E.L. (2009): Sea Nomads of the Beagle Channel in Southernmost South America: Over Six Thousand Years of Coastal Adaptation and Stability. The Journal of Island and Coastal Archaeology, 4(1): 61-81.

Pedraza, D. (2013): Las ceremonias y el mundo simbólico en la produccion y reproducción sociedades de las sociedades Yámana y Selk’nam de Tierra del Fuego. RAMPAS Revista Atlántica-Mediterránea de Prehistoria Y Arqueologia Social, 15(1): 141-164.

Pérez-Rodríguez, M.; Vila-Mitjà, A.; Estévez, J. (2016): Inequalities in "Egalitarian" Societies: The Calculation of Real Value as a Way to Visualize Social Distance. The Intangible Elements of Culture in Ethnoarchaeological Research (S. Biagetti, L. Francesca, eds.), Springer International Publishing: 293301. doi:10.1007/978-3-319-23153-2

Piana, E.; Orquera, L.A.; Estévez, J. (1992): Chronicles of "Ona-Ashaga": archaeology in the Beagle Channel (Tierra del Fuego-Argentina). Antiquity, 66: 771-783.

Piana, E.; Orquera, L.A. (1996): Túnel VII: la cronología. En Estévez y Vila-Mitjà 1996.

Piana, E.; Estévez, J.; Vila-Mitjà, A. (2000): Lanashuaia: un sitio de canoeros del siglo pasado en la costa norte del canal Beagle. Desde el país de los gigantes: perspectivas arqueológicas en Patagonia. II (J. B. Belardi, F. Carballo Marina, S. Espinosa, eds.), Univ. Nacional de la Patagonia Austral, Río Gallegos: 455-469.

Piqué, R.; Mansur, M.E. (coords.) (2012): Arqueología del Hain: investigaciones etnoarqueológicas en un sitio ceremonial de la sociedad selknam de Tierra del Fuego: implicancias teóricas y metodológicas para los estudios arqueológicos. Treballs d'etnoarqueologia 9. CSIC, Madrid.

Prentiss, A. M.; Takada, A.; Widlok, T. (2016): Review of CHAGS XI, Vienna, 2015. Hunter Gatherer Research, 2(2): 185-198.

Verdún-Castelló, E. (2014): El consumo de moluscos en sociedades cazadoras-recolectoras de Tierra del Fuego (Argentina). Cazadores de mar y tierra. Estudios recientes en arqueología fueguina (J. Oría, A. Tivoli, eds.), Editora Cultural Tierra del Fuego, Ushuaia: 363-387.

Verdún, E.; Estévez, J.; Vila-Mitjà, A. (2015): Ethnoarchaeology of Tierra del Fuego Hunter-FisherGatherer societies. The site of Lanashuaia. Forgotten Times and Spaces: New Perspectives in Paleoanthropological, Paleoetnological and Archeological Studies (S. Sázelová, M. Novák, A. Mizerová, eds.), Masaryk University, Brno: 132-154.

Vila-Mitjà, A. (2004): Proyectos etnoarqueológicos en Tierra del Fuego. Bienes Culturales, 3: 193-200.

Vila-Mitjà, A. (2006): Propuesta de evaluación de la metodología arqueológica. Etnoarqueología de la Prehistoria: más allá de la analogía, Treballs d'etnoarqueologia 6 (Departament d'Arqueologia i Antropologia IMF-CSIC, eds.), CSIC, Madrid: 13-23.

Vila-Mitjà, A. (2011): ¿Es posible obtener una muestra etnográfica para trabajar en arqueología prehistórica? Mesoamérica. Debates y perspectivas (E. Williams, M. García, P. C. Weigand, M. Gándara, eds.), Colegio de Michoacán, Zamora: 95- 114.

Vila-Mitjà, A.; Piana, E. (1993): Arguments per a una etnoarqueologia. Revista d'Etnologia de Catalunya: 151-154. 
Vila-Mitjà, A.; Piqué, R.; Mansur, E. (2004): Etnoarqueología de rituales en sociedades cazadorasrecolectoras. Catalunya-América. Fonts i documents de recerca (A. Lluís, V.G. Caballero, eds.), Institut Català de Cooperació Iberoamericana, Barcelona: 284-294.

Vila-Mitjà, A.; Casas, A.; Vicente, O. (2006): Mischiuen III, un contexto funerario singular en el Canal Beagle (Tierra del Fuego). Revista Española de Antropología Americana, 36(1): 47-61.

Vila-Mitjà, A.; Mameli, L.; Terradas, X.; Estévez, J.; Moreno, F.; Verdún, E.; Zurro, D.; Clemente, I.; Piqué, R.; Briz, I.; Barceló, J. (2007): Investigaciones etnoarqueológicas en Tierra del Fuego (1986-2006): reflexiones para la arqueología prehistórica europea. Trabajos de Prehistoria, 64(2): 37-53.

Vila-Mitjà, A.; Estévez, J.; Villatoro, D.; Sabater-Mir, J. (2010): Archaeological materiality of social inequality among hunter-gatherer societies. En Hardy 2010: 200-210.

Villagran, X.S.; Balbo, A.L.; Madella, M.; Vila-Mitjà, A.; Estévez, J. (2011): Stratigraphic and spatial variability in shell middens: microfacies identification at the ethnohistoric site Tunel VII (Tierra del Fuego, Argentina). Archaeological and Anthropological Sciences, 3(4): 357-378.

Waguespack, N.M. (2005): The Organization of Male and Female Labor in Foraging Societies: Implications for Early Paleoindian Archaeology. American Anthropologist, 107: 699-709. doi:10.1525/ aa.2005.107.4.666

Wobst, H.M. (1978): The Archaeo-Ethnology of Hunter-Gatherers or the Tyranny of the Ethnographic Record in Archaeology. American Antiquity, 43(2): 303-309.

Wünsch, G. (1996): De la articulación espacial del registro arqueológico a la gestión del espacio social: un ejemplo de aplicación del análisis de las interrelaciones espaciales (ANITES). En Estévez y Vila-Mitjà 1996: 127-142.

Wyilie, A. (1985): The Reaction Against Analogy. Advances in Archaeological Method and Theory, 8: 63111.

Zurro, D. (2010): Ni carne ni pescado (consumo de recursos vegetales en la Prehistoria): Análisis de la variabilidad de los conjuntos fitolitológicos en contextos cazadores-recolectores. Tesis doctoral. Universidad Autónoma de Barcelona. 